\title{
OS PREFIXOS NEGATIVOS: CRIAÇÃO $\epsilon$ EXPRESSIVIDADE NA POESIA DE DRUMMOND
}

\author{
Elis de Almeida Cardoso
}

RESUMO: A prefixação é um processo produtivo no português contemporâneo. Anexados a uma base, os prefixos dão-lhe significados variados. Dentre vários tipos de criação lexical, encontram-se na obra de drummond criações formadas por prefixação. Além de destacar os neologismos drummondianos, analisamos a força expressiva das criações lexicais formadas por prefixos negativos.

PALAVRAS-CHAVE: Drummond; Prefixos negativos; Criação lexical; Expressividade.

\section{INTRODUÇÃO}

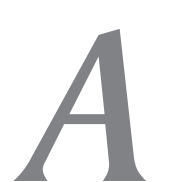

prefixação é o processo de formação de palavras por meio do qual se acrescenta a um radical ou base um prefixo. As gramáticas e os manuais que trabalham a morfologia apresentam ao estudioso uma lista de prefixos, seus significados e suas origens. Na verdade, o prefixo é um morfema gramatical derivativo e, por isso, dependente. Alguns prefixos, entretanto, apresentam um grau maior de independência e acabam por ser chamados de prefixóides ou falsos prefixos.

Para Herculano de Carvalho (1974, p. 548), os prefixóides distinguem-se dos demais prefixos por possuírem, além de um grau de independência mais acentuado, "uma significação mais ou menos delimitada e presente à consciência dos falantes, de tal modo que o significado do todo a que pertencem se aproxima de um conceito complexo, e portanto de um sintagma”. Celso Cunha (1985, p. 111-

Universidade de São Paulo. 
CARDOSO, Elis de Almeida. Os prefixos negativos: criação e expressividade na poesia...

2) concorda com Herculano de Carvalho e apresenta uma lista de pseudoprefixos da qual constam: arqui-, macro-, micro-, mini-, multi-, pluri-, entre outros.

Segundo Alves (1990, p. 15), "não há uma unanimidade, na língua portuguesa, quanto ao número e à natureza dos morfemas prefixais". A autora considera prefixos as partículas independentes ou não-independentes que, "antepostas a uma palavra-base, atribuem-lhe uma idéia acessória e manifestam-se de maneira recorrente, em formações em série".

Sandmann (1992, p. 37) compartilha dessa idéia, afirmando:

o que distingue o prefixo [de um radical] é o fato de ele expressar uma idéia geral, idéia expressa por preposições (sem-vergonha, co-ministrar), advérbios (rebatizar, não-alinhado) e adjetivos: superdocentes, não-tecido (...), ficando excluídos os substantivos e verbos, que expressam idéias particulares, com destaque, aqui, àqueles: logomania, logopedia, psicologia, psicografia.

A prefixação é um processo extremamente produtivo no português contemporâneo. Anexados a uma base, os prefixos dãolhe significados variados, como o de grandeza (super-, hiper-), de exagero (mega-), de oposição (contra-), de pequenez (mini-, micro-), entre outros.

Essa produtividade, lembra Alves (1990, p. 28), deve-se, em muitos casos, a um desejo de economia discursiva por parte do falante:

Uma frase negativa, expressa por um prefixo, torna-se mais econômica do que uma construção sintática negativa. Assim, a negação lexical permite frases como "policiais não-violentos" e "entidades ligadas aos sem-terra", ao invés de frases sintaticamente mais complexas do tipo "policiais que não são violentos' e 'entidades ligadas a aqueles que não possuem terras. ${ }^{1}$

1 Alves (1990, p. 15-7) chama a atenção para o fato de não- e sem- não serem ainda reconhecidos por gramáticos e lexicógrafos como morfemas prefixais. Para a autora, não- "prefixa-se a bases substantivas e adjetivas a fim de negar-lhes totalmente o significado" e sem- "antepõe-se a bases substantivas e tem produzido alguns neologismos substantivos em que é negada totalmente a idéia expressa pela palavra-base”. 
Filol. lingüíst. port., n. 8, p. 11-22, 2006.

\title{
2. AS CRIAÇÕES DRUMMONDIANAS FORMADAS POR PREFIXOS NEGATIVOS
}

Cumpre ressaltar que o poeta não inova em relação ao significado dos prefixos. É o resultado de uma união inesperada entre prefixo e base que surpreende o leitor.

A-

Com idéia negativa (não), o prefixo a- é erudito e une-se, em grande parte das vezes, a adjetivos. No corpus encontramos uma ocorrência em que aparece esse prefixo unido a uma base substantiva: a-gosto.

\author{
Quando contemplo teu rosto \\ este amor a contragosto \\ fermenta de ácido mosto \\ e no meu rosto de couro, \\ no meu cavername rouco \\ um dó de mim, um a-gosto \\ me punge, queima de agosto.
}

Ao formar a-gosto (Letra amarga para uma modinha - Viola de bolso), o poeta estabelece um jogo de palavras: gosto, desgosto, contragosto, a-gosto, agosto. Conforme o título avisa, a letra para a modinha é amarga; logo, uma carga de negatividade pode ser encontrada nas palavras escolhidas. Uma vez que a ausência de gosto a que o poeta se refere já é vislumbrada nas palavras desgosto e contragosto, que constam do dicionário, CDA, para acentuar essa ausência e essa negação, cria a-gosto e faz um jogo com agosto (mês), indicando quando ocorre essa, denominada por ele, "queima" interior.

\section{ANTI-}

O prefixo anti- significa basicamente contra e é exatamente esse o significado da formação drummondiana anti-petendam, encontrada no poema "Caso pluvioso" (Viola de bolso). 
CARDOSO, Elis de Almeida. Os prefixos negativos: criação e expressividade na poesia...

No poema, o eu-lírico se desespera por causa de uma chuva incessante. Para fazer com que a chuva parasse, cânticos que se dirigiam contra ela foram ouvidos. O autor cria, a partir do gerundivo latino petendam (que deve ser pedida), a forma anti-petendam. Numa analogia aos cânticos feitos para pedir chuva, sobretudo em regiões de seca (ad petendam pluviam), Drummond utiliza a forma antipetendam, referindo-se aos cânticos que imploravam a parada da chuva. Seriam ouvidos, na verdade, cânticos antichuva:

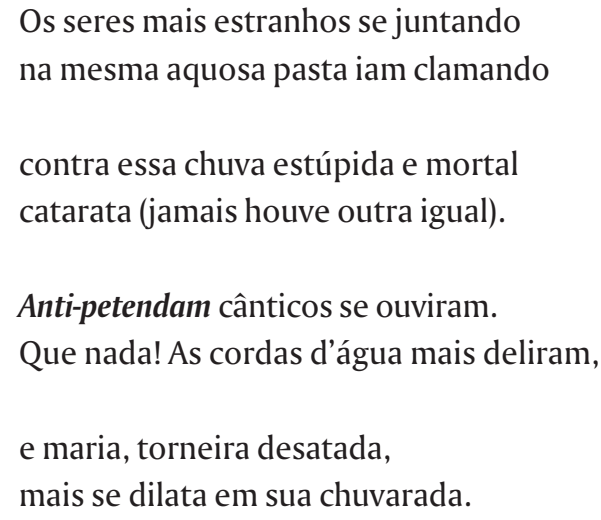

Entretanto, na formação antimúsica, retirada do poema "Beethoven" (As impurezas do branco), vê-se um novo sentido atribuído ao prefixo anti-, que é o de ruim ou de má qualidade.

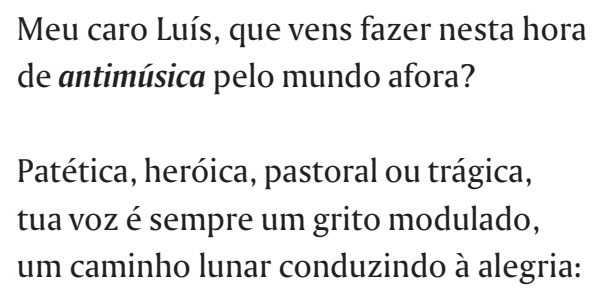

Nesta hora de antimúsica, ou seja, numa época em que as pessoas não valorizam as coisas boas, numa época em que os homens são surdos e não captam "o amor doado em sinfonia e paz", o poe- 
Filol. lingüíst. port., n. 8, p. 11-22, 2006.

ta pergunta a Ludwig van Beethoven, um dos maiores compositores clássicos da humanidade, tratado no texto por Luís, o que vem ele fazer no mundo.

O mesmo sentido de algo ruim pode ser encontrado no vocábulo anti-rosto (Viola de bolso), encontrado no já mencionado poema "Letra amarga para uma modinha":

\author{
Se te contemplo, em teu rosto \\ não me contemplo a meu gosto \\ pois teu semblante está posto \\ numa linha de sol-posto \\ em que por dentro me morro. \\ Morro de ver em teu rosto \\ o fel de teu anti-rosto.
}

Como o próprio título do poema sugere, é o amargor que predomina no coração do poeta. O rosto contemplado é um antirosto, pois só traz desgosto, contragosto e sofrimento. Os males causados ao poeta por essa pessoa resumem-se no prefixo anti-.

\title{
CONTRA-
}

Contra- é um prefixo que tem o significado geral de contrário. Além das formas dicionarizadas, encontramos no corpus a formação de contravontades em "Ao deus Kom Unik Assão" (As impurezas do branco).

No texto, o sentido do prefixo não é simplesmente o de contrário, mas também o de algo ruim ou mau. Há, na verdade, a idéia de sofrimento: "a carne pisoteada de cavalos/reclama pisaduras mais" e a vontade exige contravontades. Esse sofrimento, entretanto, parece algo fundamental, um verdadeiro vício, sem o qual as pessoas não poderiam viver.

\footnotetext{
A vontade sem vontade encrespa-se exige contravontades mais.

E se consome no consumo.
} 
DES-

O prefixo des- indica separação, transformação, intensidade, ação contrária, negação, privação. Segundo o Aurélio: "Assume, às vezes, caráter reforçativo: desafastar, desaliviar, desapagar, desbarrancado, desborcar, desencabritar, desinfeliz, desinquietar, desinquieto, desinsofrido, desnudez, despelar; e, em um caso (pelo menos), reiterativo: deslavrar".

Segundo Martins (1997, p. 121), "é com certeza o prefixo mais produtivo, mais popular, e desde as cantigas de escárnio já revelava a sua vitalidade".

Na obra poética drummondiana esse prefixo aparece inúmeras vezes em formações dicionarizadas como: desamado, desamar, desamor, destramar, desaprender, desenfado, desesperança, desimportante, entre outros.

Dentre as formas não-dicionarizadas, no poema "A torre sem degraus" ( $A$ falta que ama), encontra-se a criação desamorando. $\mathrm{O}$ poeta nos diz que em dois dos andares da torre vivem "amorosos sem amor”. Logo, se não há amor, os amorosos não podem viver amando. Eles só podem viver desamorando. Cumpre lembrar que o verbo amorar tem o significado de "fazer retirar, afugentar, esconder, ocultar, sonegar". O poeta, entretanto, usa o verbo amorar por amar e cria desamorar com o significado de não amar:

No $4^{\circ}$, no $7^{\circ}$, vivem amorosos sem amor, desamorando.

Com desbriga, percebe-se claramente a idéia de ação contrária. Ao substantivo briga é acrescentado o prefixo des-, que dá à nova palavra a idéia de se voltar atrás, fazer as pazes. A criação pode ser encontrada no subtítulo do poema "Briga e desbriga" (As impurezas do branco).

Já com desexprimo ("Ao deus Kom Unik Assão" - As impurezas do branco), a idéia de privação é muito forte. É o não poder, não conseguir exprimir-se que se manifesta nessa criação lexical. Aquele 
Filol. lingüíst. port., n. 8, p. 11-22, 2006.

que engole as idéias do Deus Kom Unik Assão só consegue desexprimir, ou seja, deixa de ter idéias próprias:

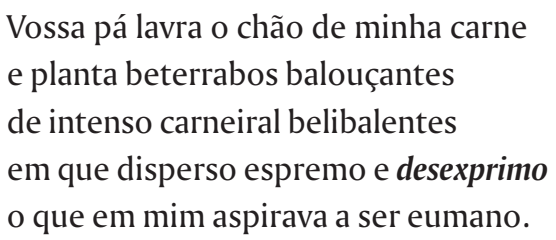

Em "A um hotel em demolição" (A vida passada a limpo), encontra-se o verbo desmorar, criado por Drummond como um antônimo para o verbo morar. O objetivo do poeta é mostrar que ele mora e desmora no "Grande Hotel do Mundo", como hóspede de si próprio:

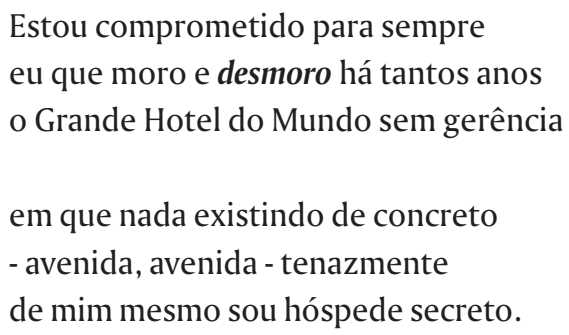

IN-

Embora existam dois prefixos in- com significados diferentes, "um com significação negativa e outro com o significado de en-" (Sandmann, 1989, p. 21), no corpus, em todas as ocorrências, criadas por Drummond, notamos a presença do significado negativo.

É extremamente comum, em português, que o prefixo in- seja anexado a uma base adjetiva em -vel, proveniente de um verbo. $\mathrm{O}$ dicionário registra muitas dessas ocorrências, mas não registra outras tantas, que podem ser consideradas formações neológicas. No corpus encontramos, dentre outras, as seguintes formações: impublicável, incochilável, infazível, infreqüentável. 
CARDOSO, Elis de Almeida. Os prefixos negativos: criação e expressividade na poesia...

Em contextos diferentes, essas criações mostram uma espécie de lamento do poeta.

Embora sejam comuns, os adjetivos impublicável e infreqüentável ganham um novo impulso semântico. Em "Apelo a meus dessemelhantes em favor da paz" (Viola de bolso), verifica-se a presença de impublicável. A opinião do "urso-polar" - caçado e trazido vivo para uma conferência - e a do poeta são impossíveis de serem publicadas, mesmo que repórteres insistam. Essas opiniões, mesmo sem serem formuladas, são contraditórias e loucas. Como não foram formuladas, não podem ser publicadas. Tem-se, então, algo impublicável. A ironia do poeta contra o fato, a notícia, o publicável, é evidente:

Não lhe, não me peçam opinião que é impublicável qualquer que seja o fato do dia e contraditória e louca antes de formulada.

Quando se pensa em um lugar infreqüentável, imagina-se um lugar com características negativas, inviável, onde a frequiência, no sentido de a permanência é desagradável. Drummond, entretanto, faz um jogo com essa palavra, dando a ela outro significado, no poema "Redator de plantão" (Esquecer para lembrar). O poeta é um redator que trabalha durante a madrugada, um redator oficial, impossibilitado de ir a concertos ou óperas, já que essas apresentações ocorrem sempre em seu horário de serviço. Quando finda seu trabalho, o teatro, para ele impossível de ser frequientado (infreqüentável), dorme:

De madrugada, findo o meu trabalho, eis dorme Clara Weiss no Grande Hotel, dorme Franz Lehar na lembrança musical de muitos, dormem lustres, mármores, sanefas do infreqüentável Teatro Municipal, e eu transporto para casa esse remorso de ser escriba, inconvicto escriba oficial. 
Filol. lingüíst. port., n. 8, p. 11-22, 2006.

Incochilável - encontrada no poema "Dormitório" (Esquecer para lembrar) - é uma "qualidade" dada ao "irmão-vigilante" que toma conta do dormitório de meninos num colégio interno, uma "prisão de luxo", segundo o poeta. Esse guardião é incochilável, sequer cochila para dar liberdade, pelo menos, ao grande sonho do menino: a fuga. Convém notar o caráter ativo desse adjetivo: o irmão incochilável é o irmão que não cochila:

No azul mortiço de oitenta camas, bóiam saudades de longes Estados, distintas casas, tantas pessoas.

Incochilável, o irmão-vigilante também passeia

sob cortinas sua memória particular?

No poema "Declaração em juízo" (As impurezas do branco), o poeta cria as formas virtuais infeito e infazível, mostrando que nada pode ser feito nem a seu favor nem contra ele, uma vez que não existe uma técnica para fazer nem para desfazer o que não foi feito - o infeito - porque não é possível fazê-lo - o infeito é infazível.

Nem há técnica

de fazer, desfazer

o infeito infazível.

Com a criação inkomunikhassão ("Ao deus Kom Unik Assão"As impurezas do branco), o poeta quer mostrar que, se as informações são manipuladas por um deus poderoso, deixa de haver comunicação, ou pior do que isso, existe a anticomunicação, chamada por ele de inkomunikhassão. Percebe-se que o prefixo in- une-se a uma base substantiva:

Senhor! Senhor!

quem vos salvará

de vossa própria, de vossa terríbil

estremendona

inkomunikhassão? 
CARDOSO, Elis de Almeida. Os prefixos negativos: criação e expressividade na poesia...

NÃO-

O prefixo não-, de caráter negativo, é um dos mais produtivos na formação de novos itens léxicos. Não é reconhecido por muitos gramáticos como prefixo, mas une-se a bases substantivas não-hóspede -, adjetivas - não-violento - ou verbais (particípio) - nãofiliado $-{ }^{2}$ com o objetivo de negar-lhes o significado.

Ao negar o significado dessas bases, o prefixo nega também suas características. O domingo, por exemplo, é o dia do descanso, um dia que se pretende feliz. No poema "O domingo e a norma" (Esquecer para lembrar), o menino comportou-se mal e recebeu um castigo: não sair no domingo. Preso em casa, o dia demora a passar, é aborrecido. Pensa nos outros lá fora, livres, e vai vivendo o seu não-domingo. Um dia que perdeu, para ele, todo o encanto de um domingo:

\author{
Que aventura doida \\ no domingo livre \\ estarão desfiando \\ enquanto eu sozinho \\ contemplo escorrer \\ a lesma infindável \\ do meu não-domingo?
}

Com a criação não-Laforgue ("Eclipse" - Versiprosa), que aparece adjetivando o substantivo verso - "Era preciso? fazer um verso não-Laforgue/ à base desse novo sentimento"-, tem-se a idéia de negação, não aplicada ao substantivo Laforgue, poeta francês, autor de Les Complaintes, e um dos criadores do verso livre. O verso nãoLaforgue é um verso com características diferentes das características utilizadas pelo poeta francês, provavelmente um verso sem estilo impressionista, com rimas e métricas:

2 Os exemplos foram retirados de Alves (1990, p. 15). 
Filol. lingüíst. port., n. 8, p. 11-22, 2006.

Era preciso?

fazer um verso não-Laforgue

à base desse novo sentimento

de lua omissa, Miss

sem desfile, sem isso

nem aquilo, só sumiço, lua eclipse.

O prefixo aparece, também, unido ao infinitivo substantivado em: não-estar, não-fazer, não-morrer-morrido, não-poder, não-saber e a formas verbais flexionadas e substantivadas em não-acaba, nãoquero, não-ter-sido. O valor de advérbio de negação é mantido em não-vê, apesar do uso do hífen.

\section{SEM-}

Assim como as preposições sobre e contra adquirem o status de prefixos, pode-se dizer que, hoje em dia, sem- adquiriu a mesma posição, embora não seja reconhecido como morfema prefixal por gramáticos e lexicógrafos, conforme lembra Alves (1990, p. 17). Na verdade, em época de crise social, é um elemento que impulsiona a criação de muitas palavras novas: sem-terra, sem-teto, sem-saúde, etc. Ao lado de formas dicionarizadas como sem-amor, sem-dinheiro, semfamilia, sem-vergonha, sem-razões, Drummond cria muitas palavras com o auxílio de sem, mantendo a idéia de privado de-: sem-fio, semjeito, sem-país, sem-palavra, sem-perfume, sem-remédio, sem-rumo, sem-sentido, sem-sono, sem-tempo e sem-véu.

\section{CONSIDERAÇÕES FINAIS}

Nota-se que as lexias criadas para um contexto específico, como é o caso das criações drummondianas, são extremamente motivadas. Nelas interagem significante e significado com o objetivo de se obter expressividade. A seguir, apresentamos as criações sintagmáticas encontradas na obra poética de CDA. 
CARDOSO, Elis de Almeida. Os prefixos negativos: criação e expressividade na poesia...

Cada prefixo unido a uma base aparece num momento específico. Nosso objetivo foi mostrar as criações e verificar por que elas trazem ao texto expressividade. Cumpre ressaltar que o poeta não inova em relação ao significado dos prefixos. É o resultado de uma união inesperada entre prefixo e base que surpreende o leitor.

\section{BIBLIOGRAFIA}

ALVES, leda Maria (1990). Neologismo: criação lexical. São Paulo: Ática.

ANDRADE, Carlos Drummond de (1983). Nova reunião. Rio de Janeiro: José Olympio, v I e II. CARVALHO, José Herculano (1974). Teoria da linguagem. Coimbra: Atlântida, v II.

CUNHA, Celso \& CINTRA, Lindley (1985). Nova gramática do português contemporâneo. Rio de Janeiro: Nova Fronteira.

FERREIRA, Aurélio Buarque de Hollanda (1999). Novo Aurélio Século XXI: o dicionário da língua portuguesa. Rio de Janeiro: Nova Fronteira.

GUILBERT, Louis (1975). La créativité lexicale. Paris: Larousse.

MARTINS, Nilce Sant'anna (1997). Introdução à Estilística. São Paulo: T.A. Queiroz/Edusp. SANDMANN, Antônio José (1989). Formação de palavras no português brasileiro contemporâneo. Curitiba: Ed. UFRP.

. (1992) Morfologia lexical. São Paulo: Contexto.

ABSTRACT: Prefixation is a productive process in the portuguese. Joining a basis, the prefixes give it different meanings. Amongst several kinds of lexical creations, those formed by prefixation are found in drummond's works. Besides emphasizing drummondian neologisms, we also analyse the significant strengh of lexical creations formed by adding negative prefixes.

KEYWORDS: Drummond; Negative prefixes; Lexical creation; Expressiveness. 